\title{
Autologous fat transfer to the subcutaneous tissue in the context of breast reconstructive procedures
}

\author{
Pawel Szychta ${ }^{1,2,3}$, Marek Zadrozny'1, Jan Rykala², Lukasz Banasiak³ ${ }^{3}$. Henryk Witmanowski ${ }^{3,4}$ \\ 1Department of Surgical Oncology and Breast Diseases, Polish Mother's Memorial Hospital Research Institute, Lodz, Poland \\ ${ }^{2}$ Department of Plastic, Reconstructive and Aesthetic Surgery, Medical University of Lodz, Lodz, Poland \\ ${ }^{3}$ Department of Plastic, Reconstructive and Aesthetic Surgery, L. Rydygier Collegium Medicum in Bydgoszcz, Nicolaus Copernicus \\ University in Torun, Poland \\ ${ }^{4}$ Department of Physiology, Poznan University of Medical Sciences, Poznan, Poland
}

Adv Dermatol Allergol 2016; XXXIII (5): 323-328

DOI: 10.5114/ada.2016.62835

\begin{abstract}
Autologous fat transfer (AFT) is an appropriate technique for aesthetic rejuvenation of the face, aesthetic enhancement of hands, correction of the facial appearance in various disorders and constitutes a surgical alternative of treatment of numerous breast deformities ranging from distorting posttraumatic scars, post-eczema lesions, postburn deformities to partial or total breast reconstruction. Our work is aimed to familiarize dermatologists with the technique of harvesting and implanting the aspirate of adipose cells in patients consulted for deformities of the breast. In addition, the review summarizes the most common applications of AFT in the breast reconstructive procedures. In summary, AFT is an oncologically safe, relatively complication-free, minimally invasive surgical technique, which can be used to correct a wide range of deformities, which are commonly seen by dermatologists, in the area of the face, trunk and extremities. The procedure can correct a wide range of breast deformities, from contour or single quadrant deformities up to the state after mastectomy.
\end{abstract}

Key words: autologous fat transfer, lipofilling, breast reconstruction.

\section{Introduction}

A wide range of anatomic areas can be treated with autologous fat injections (lipofilling) for aesthetic indications or as an adjunct to reconstructive surgery. Autologous fat transfer (AFT) is an appropriate technique for aesthetic rejuvenation of the face (i.e. forehead, eyelids, nasolabial folds, cheeks or lips), aesthetic enhancement of hands as well as for correction of the facial appearance in various disorders (such as Romberg syndrome or lipodystrophy), and also for aesthetic improvement of diverse breast contour deformities.

In relation to breasts, dermatologists and plastic surgeons frequently consult patients for a wide range of deformities, including distorting posttraumatic scars, post-eczema lesions, striae, post-burn deformities or state after sparing or radical oncological operations. In these cases, AFT constitutes an ideal surgical alternative of treatment in order to restore the optimal appearance of the distorted or amputated breast, which in turn con- tributes to restoring the mental and physical balance of the patient [1]. Promising aesthetic results after the procedure were shown in the initial reports, together with minimal donor site morbidity and invasiveness [2, 3].

Our work is aimed to familiarize dermatologists with the technique of harvesting and implanting the aspirate of adipose cells in patients consulted for deformities of the breast. In addition, the review summarizes the most common applications of AFT in the breast reconstructive procedures.

\section{Surgical procedure of autologous fat transfer}

Various procedures of adipose tissue harvesting and grafting have been described, and most of them are modifications of the Coleman fat grafting technique. Majority of surgical techniques include four main steps: infiltration, harvesting, fat processing and implantation.

Address for correspondence: Assoc. Prof. Pawel Szychta MD, PhD, DSc, Department of Surgical Oncology and Breast Diseases, Polish Mother's Memorial Hospital Research Institute, 281/289 Rzgowska St, 93-338 Lodz, Poland, phone: +48 422711101 , e-mail: szychta@yahoo.pl Received: 13.09 .2015 , accepted: 28.12.2015. 


\section{Infiltration}

Prior to harvesting of the adipose fat graft (AFG), the donor area is infiltrated with a tumescent solution. The fluid is a mixture of saline, lignocaine, adrenaline and natrium bicarbonate. The typically-used tumescent solution contains a concentration of lidocaine under 0.05\% [4]. In turn, only such high concentration of lidocaine as $2 \%$ and exposure prolonged over 20 min has a negative impact on adipocyte vitality [4].

\section{Harvesting}

The perfect anatomical region for autologous fat harvesting has not been specified [1]. Usually, the donor site is the lower abdomen or upper thigh, as based on patient's individualized preferences (Figure 1). In general, the aspirate should include adipose-derived stem cells (ADSCs). Adipose-derived stem cells increase the regenerative potential and improve blood circulation in the recipient site [5]. Here, it must be emphasized that the post-mastectomy area should not be exposed to increased concentrations of growth factors and elevated ratios of stem cells with their stimulating effect on surrounding tissues. There is a wide variety of harvesting methods, which mostly include conventional liposuction or syringe aspirations [6-12]. So far, there have been no reports showing a difference in the graft survival rate in relation to the harvesting method. Rationally, low pressure and blindly tipped cannula with side holes is an optimal solution for harvesting the adipose cells [13].

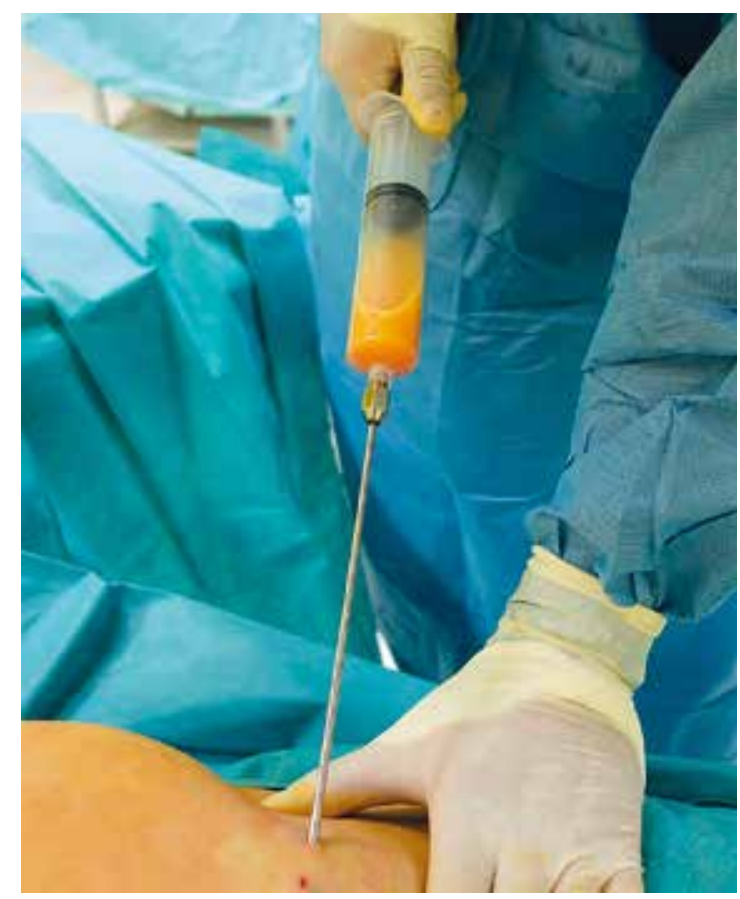

Figure 1. Aspiration of adipose cells from the anterior abdominal wall

\section{Fat processing}

The aspirate is processed in order to obtain a higher concentration of cells as well as to eliminate the tumescent solution, free fatty acids and blood remnants. The resulting mixture of adipocytes, ADSCs and growth factors guarantees more predictable outcomes. Currently, there are three commonly used methods of processing AFG: sedimentation by gravity, filtering technique and centrifugation. Each of the methods seems to have unique benefits. There is no consensus which one is the most effective.

In detail, AFT prepared by sedimentation are much more viable than adipocytes decanted by centrifugation. Materials prepared using this method contain a significant amount of contaminating blood cells and smaller concentrations of stem cells [14].

Centrifugation removes most of free fat and remaining blood (Figure 2). This method obtains the highest possible concentration of stem cells within aspirate. It has also the increased content of angiogenic growth factors such as fibroblast growth factor (FGF) and vascular endothelial growth factor (VEGF) [15]. The optimal speed of rotation has been initially specified as 3000 rpm (approx. 1286 g) for 3 min [16]. Additionally, the adipocyte fraction after centrifugation is characterized with the highest density, which increases the survival and predictability of the final outcome [17]. However, centrifugation seems to be more traumatic for adipocytes due to the larger forces acting on aspirate.

In an open method, the lipoaspirate is filtered with cotton gauze, which results in concentrating the fat and separating it from the tumescent fluid, oily substances and cellular debris. The above method, as compared to centrifugation, showed no significant differences in vitality of transplant [18]. The open method is more exposed to aspirate contamination [19]. Histological examination of the transplanted fat showed a much lesser degree of fibrosis in the healing process than in other processing methods [18].

A number of studies examined the effectiveness of enrichment AFG substances to enhance the overall effect - tissue graft survival. Studies did not confirm the benefits of AFT enrichment in platelet-rich plasma [20]. Studies also showed no profits of the use of stem cell enrichment by the Celution ${ }^{\circledR}$ [21]. Enrichment prolongs the procedure, and the high price of the equipment increases the final cost of the procedure [22].

In general, choice of method is not cardinal for the final results; each of the methods may have a specific indication for the use. Due to the wide distribution of classical methods and their low costs, they still seem to be the first choice of fat processing. 

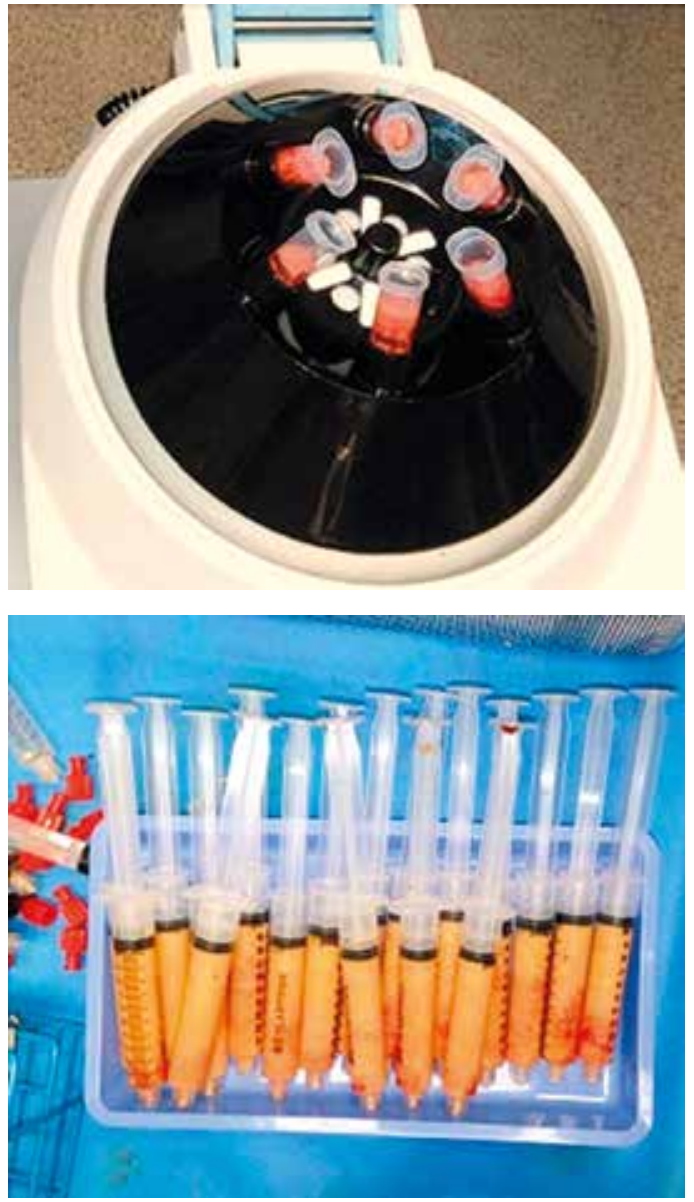

\section{Implantation}

The optimal implantation technique is crucial to obtain long-lasting results. The recipient area should be considered as a three-dimensional structure. Graft through nutrition by tissue fluid absorption can survive up to $48 \mathrm{~h}$. In the meantime, neovascularization progresses with the rate of about $1 \mathrm{~mm}$ per day. Therefore, the diameter of the deposit should not ideally be greater than $2 \mathrm{~mm}$ to avoid central necrosis $[23,24]$. The key strategy following the above rule is implantation of AFG in the form of microdroplets or microribbons $[23,24]$. On contrary, a single bolus injection of a large amount of fat causes a poor survival rate and fat necrosis [25].

Very high efficiency has been proven for multi-level, parallel administration of AFT in the fanlike model. Small amounts of approximately $0.03 \mathrm{ml}$ of AFG are administered on withdrawal of the cannula. This ensures a high survival rate of the transplant and uneventful healing, thus increases the predictability of treatment [24].

Tissue volumetric capacity of AFG is based not only on ability to adopt further cells and a potential for providing a blood supply. Implanting the transplant increases the interstitial fluid pressure level. When the interstitial

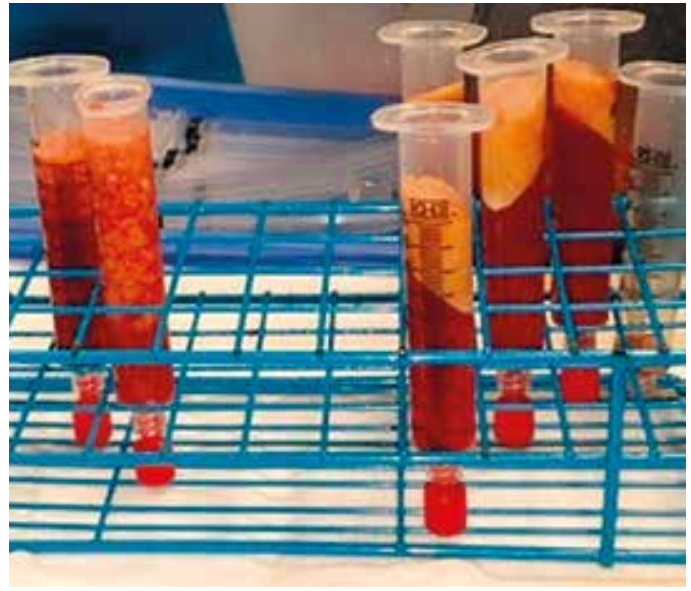

Figure 2. Centrifugation of aspirate obtained for lipofilling of the breast

fluid pressure exceeds the pressure in the capillaries, the collapse thereof occurs. It exposes tissues to hypoxia and prevents proper healing of the graft [23]. Exceeding the maximal capacity of the tissues may lead to loss of the whole transplant.

Even large volumes of AFG can be applied following the above general rules $[24,26]$.

\section{Partial breast reconstruction with autologous fat transfer following breast conserving therapy (BCT) or oncoplastic surgery}

In some patients, aesthetic results following breast conserving therapy (BCT) or oncoplastic surgery and after radiotherapy can be less than suboptimal. Here, the minimally invasive partial breast reconstruction with adipose cells exclusively is satisfactory for the vast majority of patients, and can even enhance the quality of tissues after radiotherapy [27].

The advantages of simultaneous reconstruction are indisputable; however, the required subsequent radiotherapy can disrupt the outcome. The method of delayed partial breast reconstruction with AFT is proposed for 
most patients, especially with a tumour of low malignant potential [27].

Adipose fat graft should be implanted as a fan-like technique in multiple planes to correct deformities, with caution to maintain an appropriate distance from the tumour lodge. Autologous fat transfer should never be administered to the tumour bed. It is also not advisable to administer the graft to glandular tissues. The procedure should not expose the tumour bed to contact with the increased ratio of growth factors produced by stromal cells or transferred with the graft [28]. Therefore, the lowest possible content of growth factors should be administrated with graft.

\section{Autologous fat transfer and implant-based breast reconstruction}

Two-stage expander and implant-based breast reconstruction is one of the most common surgical options done in Europe and the United States [29]. The technique is associated with a relatively high rate of complications, which is even elevated after radiotherapy. A combination of implants and AFT enhances the final effect of the reconstruction in patients with or without radiotherapy [30].

Autologous fat transfer minimizes the complications rate related to use of the implant regarded as a foreign body and the total risk of reconstruction failure is minimized. Autologous fat transfer could be used for prevention of implant exposure [31]. A decreased ratio of implant exposure incidents is due to the improved quality of tissues with the increased thickness of subcutaneous tissue in cases of very thin coverage layers [29]. These advantages are more evident in patients with the irradiated skin. Autologous fat transfer is undertaken at least 6 weeks after radiotherapy [30].

Breast reshaping with AFT helps to release any contractures and correct contour distortions [32]. Reduced fibrosis caused by AFG decreases the risk of high-grade capsular contracture $\left(3^{\text {rd }}-4^{\text {th }}\right.$ grade on the Becker scale) [33].

\section{Autologous fat transfer and breast reconstruction with autologous tissue flaps}

Breast reconstruction with autologous flaps can lead to excellent aesthetic results, usually superior to the implantbased procedure [32]. Common problems in flap reconstruction are donor site morbidity or inadequate tissue volume. Morbidity of the donor site has already been downgraded with use of perforator flaps, where only skin and adipose tissue are harvested. In turn, breast volume can be increased with additional implant or overlapping flaps [34].

More and more commonly, autologous reconstructions can be complemented also with AFT. Autologous fat transfer corrects contour irregularities, refills spherical disturbances and smoothens scars [35]. Nowadays, the flap becomes a recipient to AFT for further reshaping stages $[36,37]$. In both instances, AFG is usually implant- ed in numerous tunnels subcutaneously and into the adipose tissue of the flap as soon as 6 weeks following the primary procedure. Significant and long-lasting improvement of the reconstructed breast shape is obtained.

\section{Autologous fat transfer as an adjunct to breast reconstruction after radiotherapy}

Radiotherapy is required as part of oncological treatment of breast cancer in patients subjected to tissue sparing surgery, those with selected tumour locations and staging or with the metastatic lymph nodes [38]. Unfortunately, radiotherapy reduces the aesthetic outcomes of BCT, deteriorates the surgical outcome of primary and secondary breast reconstruction [39].

Irradiated tissues are prone to excessive accumulation of subcutaneous collagen as well as dermatitis, fibrosis and inflammation [40, 41]. Autologous fat transfer decreases all the above traits of the damaged, irradiated tissues [39]. The role of growth factors and angiogenesis is extensively studied in order to understand the underlying mechanism [31].

\section{Breast reconstruction exclusively with autologous fat transfer}

In selected patients, AFT has become an independent reconstructive method due to advances in the surgical technique [42]. Breast reconstruction exclusively with AFT offers many advantages: full biocompatibility, the ease of obtaining material, potentially large volume available, a relatively simple surgical technique, low risk for the patient, and avoidance of general anaesthesia. Irradiation does not decrease the AFG survival rate, however it can limit the potential for pleasing aesthetic outcome [26].

It is suggested that external vacuum therapy is essential for total breast reconstruction with AFT exclusively. It extends and prepares the tissue scaffold and skin envelope for the larger volume of the implanted graft. The negative pressure increases breast tissue vascularization. There are reports that therapy has locally increased the amount of stromal cells and growth factors. There are promising reports of beneficial effects of external vacuum therapy like BRAVA on reconstructed tissues [43]. BRAVA allows for good results in highly motivated patients [44]. The reconstruction should be carried out in multiple sessions. It should consist of two main parts. The purpose of the first low-volume part is to improve local conditions. Autologous fat transfer creates a fatty space in scarred tissues. The second part is a proper volume reconstruction, which is administration of large amounts of fat. The minimum interval between administrations should be at least 21 days [45]. At this time, the transplanted fat develops vascularization similar to that of normal tissues [46].

Breast reconstruction with AFT is relatively easy and requires less experience and clinical skills than other 
surgical techniques. Autologous fat transfer can still be used when other options have failed or are not suitable. The method can be even considered in patients after the failed implant-based breast reconstruction, where the common autologous flaps are not available or contraindicated [30]. A multicentre report has shown that the incidence of complications in the fatty tissue reconstruction is less than 3\% [47]. The complications rate increases when there is a tendency to overgraft [32].

\section{Oncological safety}

Autologous fat transfer was previously suspected of delaying the oncological diagnosis of local recurrences. Therefore, it was excluded as a method of breast reconstruction for a long time. Research on the oncological safety and possibilities of using AFT in the post-mastectomy patients has significantly intensified after the statement of the American Society of Plastic Surgery on AFT [48]. Autologous fat transfer does not increase the risk of local recurrence and distant metastases and oncological safety has been confirmed both experimentally and in clinical trials, with short- and long-term follow-up [49-51]. The incidence of recurrence in patients subjected to AFT is statistically identical to patients who do not undergo reconstruction [51].

There are significant differences in the mammographic image, ultrasound and magnetic resonance imaging between the suspected cancer and benign lesions after AFT [52]. A radiologist experienced in breast diagnostics should be able to differentiate between potentially malignant changes and any changes following AFT [53].

\section{Summary}

Autologous fat transfer is an oncologically safe, relatively complication-free, minimally invasive surgical technique, which can be used to correct a wide range of deformities, which are commonly seen by dermatologists, in the area of the face, trunk and extremities. The procedure can correct a wide range of breast deformities, from contour or single quadrant deformities up to the state after mastectomy. In the reconstructive cases, the procedure can act as an adjunct to any common autologous or implant-based options. Autologous fat transfer can be also used as an independent method of breast reconstruction, especially when used with an external expander. Additionally, the procedure is perfectly suited for symmetrisation.

\section{Acknowledgments}

This work was supported by statutory research task No. 2014/VII/27-SZB in the Polish Mother's Memorial Hospital Research Institute in Lodz, Poland.

\section{Conflict of interest}

The authors declare no conflict of interest.

\section{References}

1. Ferlay J, Soerjomataram I, Dikshit R, et al. Cancer incidence and mortality worldwide: sources, methods and major patterns in GLOBOCAN 2012. Int J Cancer 2015; 136: E359-86.

2. Rubio IT. Breast conservative surgery in breast cancer: simple can be harder than complex. J Surg Oncol 2014; 110: 1.

3. Szychta P, Raine C, Butterworth M, et al. Preoperative implant selection for two stage breast reconstruction with 3D imaging. Comput Biol Med 2014; 44: 136-43.

4. Keck M, Zeyda M, Gollinger K, et al. Local anesthetics have a major impact on viability of preadipocytes and their differentiation into adipocytes. Plast Reconstr Surg 2010; 126: 1500-5.

5. Pu LL. Towards more rationalized approach to autologous fat grafting. J Plast Reconstr Aesthet Surg 2012; 65: 413-9.

6. Karacalar A, Orak I, Kaplan S, Yildirim S. No-touch technique for autologous fat harvesting. Aesthetic Plast Surg 2004; 28: 158-64.

7. Nguyen A, Pasyk KA, Bouvier TN, et al. Comparative study of survival of autologous adipose tissue taken and transplanted by different techniques. Plast Reconstr Surg 1990; 85: 378-86.

8. Pu LL, Cui X, Fink BF, et al. The viability of fatty tissues within adipose aspirates after conventional liposuction: a comprehensive study. Ann Plast Surg 2005; 54: 288-92.

9. von Heimburg D, Hemmrich K, Haydarlioglu S, et al. Comparison of viable cell yield from excised versus aspirated adipose tissue. Cells Tissues Organs 2004; 178: 87-92.

10. Boschert MT, Beckert BW, Puckett CL, Concannon MJ. Analysis of lipocyte viability after liposuction. Plast Reconstr Surg 2002; 109: 761-5.

11. Pu LL, Coleman SR, Cui X, et al. Autologous fat grafts harvested and refined by the Coleman technique: a comparative study. Plast Reconstr Surg 2008; 122: 932-7.

12. Erdim M, Tezel E, Numanoglu A, Sav A. The effects of the size of liposuction cannula on adipocyte survival and the optimum temperature for fat graft storage: an experimental study. J Plast Reconstr Aesthet Surg 2009; 62: 1210-4.

13. Gonzalez AM, Lobocki C, Kelly CP, Jackson IT. An alternative method for harvest and processing fat grafts: an in vitro study of cell viability and survival. Plast Reconstr Surg 2007; 120: 285-94.

14. Conde-Green A, de Amorim NF, Pitanguy I. Influence of decantation, washing and centrifugation on adipocyte and mesenchymal stem cell content of aspirated adipose tissue: a comparative study. J Plast Reconstr Aesthet Surg 2010; 63: 1375-81.

15. Pallua N, Pulsfort AK, Suschek C, Wolter TP. Content of the growth factors bFGF, IGF-1, VEGF, and PDGF-BB in freshly harvested lipoaspirate after centrifugation and incubation. Plast Reconstr Surg 2009; 123: 826-33.

16. Kim IH, Yang JD, Lee DG, et al. Evaluation of centrifugation technique and effect of epinephrine on fat cell viability in autologous fat injection. Aesthet Surg J 2009; 29: 35-9.

17. Canizares OSC, Nguyen PD. Centrifugation creates unique fractions of lipoaspirate: implications for fat graft survival. Plast Reconstr Surg 2009; 126 (Suppl.): 75.

18. Ramon Y, Shoshani O, Peled IJ, et al. Enhancing the take of injected adipose tissue by a simple method for concentrating fat cells. Plast Reconstr Surg 2005; 115: 197-201. 
19. Mestak O, Sukop A, Hsueh YS, et al. Centrifugation versus PureGraft for fatgrafting to the breast after breast-conserving therapy. World J Surg Oncol 2014; 12: 178.

20. Salgarello M, Visconti G, Rusciani A. Breast fat grafting with platelet-rich plasma: a comparative clinical study and current state of the art. Plast Reconstr Surg 2011; 127: 2176-85.

21. Peltoniemi HH, Salmi A, Miettinen S, et al. Stem cell enrichment does not warrant a higher graft survival in lipofilling of the breast: a prospective comparative study. J Plast Reconstr Aesthet Surg 2013; 66: 1494-503.

22. Kølle SF, Fischer-Nielsen A, Mathiasen AB, et al. Enrichment of autologous fat grafts with ex-vivo expanded adipose tissue-derived stem cells for graft survival: a randomised placebo-controlled trial. Lancet 2013; 382: 1113-20.

23. Khouri RK, Rigotti G, Cardoso E, et al. Megavolume autologous fat transfer: part I. Theory and principles. Plast Reconstr Surg 2014; 133: 550-7.

24. Khouri RK, Rigotti G, Cardoso E, et al. Megavolume autologous fat transfer: part II. Practice and techniques. Plast Reconstr Surg 2014; 133: 1369-77.

25. Sherman JE, Fanzio PM, White H, Leifer D. Blindness and necrotizing fasciitis after liposuction and fat transfer. Plast Reconstr Surg 2010; 126: 1358-63.

26. Boyce M, Radtke C, Vogt PM. The volumetric analysis of fat graft survival in breast reconstruction. Plast Reconstr Surg 2013; 132: 862e-3e.

27. Moltó García R, González Alonso V, Villaverde Doménech ME. Fat grafting in immediate breast reconstruction. Avoiding breast sequelae. Breast Cancer 2016; 23: 134-40.

28. Kijima Y, Yoshinaka H, Funasako Y, et al. Immediate breast reconstruction using autologous free dermal fat grafts provides better cosmetic results for patients with upper inner cancerous lesions. Surg Today 2011; 41: 477-89.

29. Ribuffo D, Atzeni M, Guerra M, et al. Treatment of irradiated expanders: protective lipofilling allows immediate prosthetic breast reconstruction in the setting of postoperative radiotherapy. Aesthetic Plast Surg 2013; 37: 1146-52.

30. Sarfati I, Ihrai T, Kaufman G, et al. Adipose-tissue grafting to the post-mastectomy irradiated chest wall: preparing the ground for implant reconstruction. J Plast Reconstr Aesthet Surg 2011; 64: 1161-6.

31. Panettiere P, Marchetti L, Accorsi D. The serial free fat transfer in irradiated prosthetic breast reconstructions. Aesthetic Plast Surg 2009; 33: 695-700.

32. Lakhiani C, Hammoudeh ZS, Aho JM, et al. Maximizing aesthetic outcome in autologous breast reconstruction with implants and lipofilling. Eur J Plast Surg 2014; 37: 609-8.

33. Serra-Renom JM, Munoz-Olmo IL, Serra-Mestre JM. Fat grafting in postmastectomy breast reconstruction with expanders and prostheses in patients who have received radiotherapy: formation of new subcutaneous tissue. Plast Reconstr Surg 2010; 125: 12-8.

34. DellaCroce FJ, Sullivan SK, Trahan C. Stacked deep inferior epigastric perforator flap breast reconstruction: a review of 110 flaps in 55 cases over 3 years. Plast Reconstr Surg 2011; 127: 1093-9.

35. de Blacam C, Momoh AO, Colakoglu S, et al. Evaluation of clinical outcomes and aesthetic results after autologous fat grafting for contour deformities of the reconstructed breast. Plast Reconstr Surg 2011; 128: 411e-8e.

36. Sinna R, Delay E, Garson S, et al. Breast fat grafting (lipomodelling) after extended latissimus dorsi flap breast reconstruction: a preliminary report of 200 consecutive cases. J Plast Reconstr Aesthet Surg 2010; 63: 1769-77.
37. Bonomi R, Betal D, Rapisarda IF, et al. Role of lipomodelling in improving aesthetic outcomes in patients undergoing immediate and delayed reconstructive breast surgery. Eur J Surg Oncol 2013; 39: 1039-45.

38. Sarfati I, Ihrai T, Duvernay A, et al. Autologous fat grafting to the postmastectomy irradiated chest wall prior to breast implant reconstruction: a series of 68 patients. Ann Chir Plast Esthet 2013; 58: 35-40.

39. Phulpin B, Gangloff P, Tran N, et al. Rehabilitation of irradiated head and neck tissues by autologous fat transplantation. Plast Reconstr Surg 2009; 123: 1187-97.

40. Sultan SM, Stern CS, Allen RJ Jr, et al. Human fat grafting alleviates radiation skin damage in a murine model. Plast Reconstr Surg 2011; 128: 363-72.

41. Choi M, Small K, Levovitz C, et al. The volumetric analysis of fat graft survival in breast reconstruction. Plast Reconstr Surg 2013; 131: 185-91.

42. Czerny V. Plastischer Ersatz der Brustdrüse durch ein Lipom. Arch F Klin Chir 1895; 50: 544-50.

43. Khouri R, Del Vecchio D. Breast reconstruction and augmentation using pre-expansion and autologous fat transplantation. Clin Plast Surg 2009; 36: 269-80.

44. Kato H, Suga H, Eto H, et al. Reversible adipose tissue enlargement induced by external tissue suspension: possible contribution of basic fibroblast growth factor in the preservation of enlarged tissue. Tissue Eng Part A 2010; 16: 2029-40.

45. Longo B, Laporta R, Sorotos M, et al. Total breast reconstruction using autologous fat grafting following nipple-sparing mastectomy in irradiated and non-irradiated patients. Aesthetic Plast Surg 2014; 38: 1101-8.

46. Neels JG, Thinnes T, Loskutoff DJ. Angiogenesis in an in vivo model of adipose tissue development. FASEB J 2004; 18 : 983-5.

47. Petit JY, Lohsiriwat V, Clough KB, et al. The oncologic outcome and immediate surgical complications of lipofilling in breast cancer patients: a multicenter study-Milan-Paris-Lyon experience of 646 lipofilling procedures. Plast Reconstr Surg 2011; 128: 341-6.

48. Villani F, Caviggioli F, Giannasi S, et al. Current applications and safety of autologous fat grafts: a report of the ASPS Fat Graft Task Force. Plast Reconstr Surg 2010; 125: 758-9.

49. Kucerova L, Skolekova S, Matuskova M, et al. Altered features and increased chemosensitivity of human breast cancer cells mediated by adipose tissue-derived mesenchymal stromal cells. BMC Cancer 2013; 13: 535-47.

50. Petit JY, Botteri E, Lohsiriwat V, et al. Locoregional recurrence risk after lipofilling in breast cancer patients. Ann Oncol 2012; 23: 582-8

51. Rigotti G, Marchi A, Stringhini P, et al. Determining the oncological risk of autologous lipoaspirate grafting for postmastectomy breast reconstruction. Aesthetic Plast Surg 2010; 34: 475-80.

52. Rubin JP, Coon D, Zuley M, et al. Mammographic changes after fat transfer to the breast compared with changes after breast reduction: a blinded study. Plast Reconstr Surg 2012; 129: 1029-38

53. Veber M, Tourasse C, Toussoun G, et al. Radiographic findings after breast augmentation by autologous fat transfer. Plast Reconstr Surg 2011; 127: 1289-99. 